\title{
Comparison of Pyogenic Spondylitis and Tuberculous Spondylitis
}

\author{
Kyu Yeol Lee \\ Department of Orthopedic Surgery, Dong-A Medical Center, Dong-A University College of Medicine, Busan, Korea
}

Pyogenic spondylitis and tuberculous spondylitis are common causes of spinal infection. It is difficult to differentiate tuberculous spondylitis and pyogenic spondylitis clinically and radiologically. Recently magnetic resonance imaging has been reported to be beneficial for early diagnosis and differential diagnosis of the spondylitis, and is being used extensively for diagnosis. However, the diagnosis must be considered in combination with corresponding changes in clinical manifestations, radiological findings, blood and tissue cultures and histopathological findings. Conservative treatments, including antimicrobial medications, are started initially. Surgical treatments, which include anterior or posterior approach, single-stage or two-stage surgery, with or without instrumentation, may be performed as indicated.

Keywords: Pyogenic spondylitis; Tuberous spondylitis; Differential diagnosis

\section{Introduction}

Pyogenic spondylitis and tuberculous spondylitis are common causes of spinal infection. The current trend is a decrease in spinal infections due to good nutritional and hygienic status, but an increase in the resistant strains of the organism of pyogenic spondylitis [1,2]. Tuberculous spondylitis has been common in developing countries, and the number of patients with the disease has also been increasing recently in developed countries $[1,3-5]$. Tuberculosis of the spine accounts for $1 \%$ of all tuberculous infections, and $25 \%$ to $60 \%$ of all bone and joint infections are caused by tuberculosis $[1,6]$. It is important to differentiate tuberculous spondylitis from pyogenic spondylitis, because proper treatment for the different types may reduce the rate of disability and functional impairment $[1,6,7]$. However, it is difficult to differentiate tuberculous spondylitis from pyogenic spondylitis clinically and radiologically $[8,9]$. The objective of this review is to discuss the symptoms, laboratory findings, magnetic resonance imaging (MRI) evaluations and management of the two spinal infections according to recent literature.

\section{Classification}

There are various classification methods for spine infections. The most basic is by the histologic response of the host to the specific organism [10]. Aetiologically spinal infections can be described as pyogenic, granulomatous and parasitic. Most bacteria cause a pyogenic response, whereas Mycobacteria, fungi, Brucella, and syphilis induce granulomatous reactions $[11,12]$. Other ways of classifying spinal infections are by the primary anatomic location or spread route. Anatomical classifications in-

Received Aug 26, 2013; Revised Oct 14, 2013; Accepted Oct 16, 2013

Corresponding author: Kyu Yeol Lee

Department of Orthopedic Surgery, Dong-A Medical Center, Dong-A University College of Medicine,

26 Daesingongwon-ro, Seo-gu, Busan 602-715, Korea

Tel: +82-51-240-2867, Fax: +82-51-243-9764, E-mail: gylee@dau.ac.kr 
clude vertebral osteomyelitis, discitis, and epidural abscess. Hematogenous, direct inoculation and spread from a contiguous source are also used in the categorization by spread route.

\section{Incidence}

Various reports have stated that pyogenic spondylitis is relatively rare and represents $0.15 \%$ to $3.9 \%$ of all osteomyelitis cases $[13,14]$. Vertebral osteomyelitis is more common in the lumbar region, followed by thoracic and cervical spine (less than 10\%) [13-15]. Bone and joint involvement develops in approximately $10 \%$ of patients with tuberculosis, and half of these affected patients have tuberculosis of the spine $[12,16,17]$. In several studies, the thoracic spinal vertebrae have been found as the most common areas of tuberous infection, followed by lumbar and thoracolumbar spine (in descending order by rate). In pyogenic spondylitis, the lumbar spine is the most common area of infection, followed by thoracic and cervical spine (less than 10\%) $[13,15,17,18]$.

\section{Aetiology and Bacteriology}

While a wide range of organisms have been associated with spondylodiscitis (bacterial, Mycobacterial, fungal, and parasitic), it remains primarily a monomicrobial bacterial infection. Staphylococcus aureus is the predominant pathogen, accounting for half of non-tuberculous cases (range, 20\%-84\%). Streptococci (viridans type and b-haemolytic streptococci, particularly groups A and B) and enterococci are well known to be causes of spondylodiscitis (5\%-20\%) $[19,20]$. The most frequently isolated gram-negative organisms are Escherichia coli, Pseudomonas species, and Proteus species. These are frequently found in association with genitourinary tract infection. In addition the probable sources of infection are those of soft tissue and respiratory tract among others. Most common causes of iatrogenic disc infection are spinal surgery and invasive manipulation [21-23]. Tuberculous spondylitis is most commonly caused by Mycobacterium tuberculosis, but any species of Mycobacterium may be responsible [24].

\section{Pathogenesis and Pathology}

Infective spondylitis may result from hematogenous spread, direct external inoculation or from contiguous tissues. The hematogenous arterial route is predominant, allowing seeding of infection from distant sites onto the vertebral column. Wiley and Trueta [25] demonstrated that metaphyses and cartilaginous end plates are starting areas for blood-borne infections, showing how bacteria could easily spread hematogenously to the metaphyseal region of adjacent vertebrae [26]. In pyogenic spondylitis, once microorganisms enter in vascular arcades in the metaphysis, the infection spreads. The disc is destroyed by bacterial enzymes in a manner similar to the destruction of cartilage in septic arthritis. Pyogenic infection commonly involves the thoracic and lumbar spines. In contrast to pyogenic infections, tuberculous infection commonly results from venous spread, Batson's paravertebral venous plexus. Tuberculous spondylitis typically involves initial destruction of the anteroinferior part of vertebral bodies and may then spread beneath the anterior spinal ligament, involving the anterosuperior aspect of adjacent inferior vertebra. Further spread may result in adjacent abscesses [27]. Anterior type involvement of the vertebral bodies seems to be due to the extension of an abscess beneath the anterior longitudinal ligaments and the periosteum. However, tuberculous spondylitis does not destroy the disc until very late in the disease.

\section{Prevalence and Clinical Manifestation}

Tuberculous spondylitis has been reported to entail a relatively long, insidious progress from the occurrence and diagnosis compared to pyogenic spondylitis $[1,28]$. Lee et al. [28] described that for pyogenic spondylitis, it took on average 6.4 months for the occurrence of clinical signs, which include non-specific pain, fever and neurological manifestation from the compression on spinal cord and nerve root. For tuberculous spondylitis, it was 11.2 months on average. Hence pyogenic spondylitis takes a shorter duration for the clinical signs. Buchelt et al. [2] reported that the prevalence period of tuberculous spondylitis was significantly longer than that of pyogenic spondylitis. In addition, Colmenero et al. [7] has reported that tuberculous spondylitis has an approximately 6-months prevalence period. As for tuberculous spondylitis, there were almost no clinical sings such as fever, pain or swelling due to infection and entailed a gradual progress of disease. However, pyogenic spondylitis most likely entails severe pain and high fever $[1,6]$. The results 
Table 1. Distinctive clinical findings of pyogenic and tuberculous spondylitis

\begin{tabular}{lll} 
Variable & Pyogenic spondylitis & Tuberculous spondylitis \\
Fever & More frequent associated high fever & Intermittent fever \\
\hline Age & Relatively old & Relatively young \\
\hline Duration to diagnosis & Relatively short symptom to diagnosis interval & Relatively long symptom to diagnosis interval \\
ESR, CRP & Markedly increased ESR, CRP & Mildly increased ESR, CRP \\
\hline
\end{tabular}

ESR, erythrocyte sedimentation rate; CRP, C-reactive protein.

of the most distinctive clinical findings for pyogenic and tuberculous spondylitis are summarized in Table 1 $[28,29]$.

\section{Diagnosis}

The definitive diagnosis of spinal spondylitis can only be made from microscopic or bacteriological examination and culture of the infected tissue. However the diagnosis must be considered in combination with corresponding changes in clinical manifestations, radiological findings, blood and tissue cultures and histopathological findings.

\section{Laboratory evaluation}

The erythrocyte sedimentation rate (ESR) and gram stain and culture are the commonly used laboratory tests in the diagnosis of pyogenic spine infections [30]. C-reactive protein (CRP) has been shown to be helpful in the diagnosis of infection and has supplanted ESR as the laboratory study of choice for assessing the presence of infection [31]. Koo et al. [29] described that the ESR and CRP level were significantly higher in the patients with pyogenic spondylitis than tuberous spondylitis. Polymerase chain reaction has been used to rapidly identify the presence of mycobacterium in formaldehyde solution-fixed, paraffinembedded tissue specimens [32].

\section{Plain radiologic evaluation}

The earliest and most common radiographic finding is narrowing of the disc space in pyogenic spondylitis. It is due to the disc destruction by proteolytic enzyme and is followed by irregularity of endplate from the bone destruction. In progression and healing of the disease, osteolytic changes are followed by new bone formation and osteosclerotic changes at the vertebral margins $[21,23]$. The findings of plain radiographs for tuberous spondylitis may vary depending on the pathologic type and chronicity of the infection. In early tuberous spondylitis, the disc space is preserved more than pyogenic spondylitis from the lack of proteolytic enzyme. Radiographs may show osteoporosis of body and irregularity of endplate, among others.

\section{Magnetic resonance imaging}

MRI has been reported to be beneficial for early diagnosis and differential diagnosis of the spondylitis and is being extensively used for diagnosis [1,7,33-35]. The typical MRI findings of acute vertebral myelitis are low signal intensity in the T1-weighted images and high signal intensity in the T2-weighted images, due to edema of bone marrow in the infected area. However the value of differential diagnosis is low, as there is no specific difference in the contagious causes. In the chronic progress with delayed diagnosis, high signal intensity is sometimes shown in the T1-weighted images $[3,34,36,37]$. In addition low signal intensity is shown in both $\mathrm{T} 1$ and T2-weighted images, if vertebral body has progressed to a collapse and has irregular endplate sclerosis. Hence contrast enhancement images of the gadolinium are specifically required $[3,37]$. As the MRI is generalized, specific opinions that are beneficial to differential diagnosis of tuberculous spondylitis are being reported by various authors (Figs. $1,2)$. Representative opinions deal with abscess in the vertebral body showing contrast enhancement in the peripheral rim, erosion of vertebral body surface, paraspinal abscess with relatively clear border that shows contract peripheral enhancement, extension of anterior longitudinal ligament of the inflammatory tissue and relatively preserved disk $[8,34,38,39]$. As for tuberculous spondylitis, it typically starts from the anterior cancellous bone in the vertebral body followed by vertebral body starting to be destructed, extending beneath anterior longitudinal ligament and creating an abscess near the vertebral body 
$[1,3,40]$. Many of the studies dealing with tuberculous spondylitis have reported that abscess involves uniquely multiple vertebral bodies, especially in gadoliniumenhanced MRIs [34,35,41]. Chang et al. [41] has reported that aforementioned form of contrast enhancement is completely shown in tuberculous spondylitis. Destruction of vertebral bodies in tuberculous spondylitis entails more of such contrast enhancement. It is assumed that abscess is formed more and also available to be used for beneficial indices when performing a differential diagnosis. Epidural extension and epidural abscess formation have been reported to be observed more in tuberculous spondylitis $[35,41]$. As for paraspinal abscess formed in tuberculous spondylitis, contrast enhancement is known to be more easily performed in the rim of abscess, with the importance of a differential diagnosis $[4,41]$. In other words, paraspinal abscess is frequently found in pyogenic spondylitis; but well-defined paraspinal abnormal signal, thin and smooth abscess wall and presence of paraspinal or intraspinal abscess are more suggestive of tuberculous spondylitis than of pyogenic spondylitis. On the other hand, if the wall of abscess is relatively thick entailing irregular contrast enhancement, it has been reported to be implying pyogenic spondylitis $[30,34,42]$. Chang et al. [41] has reported that cases with grade 3 or above and destructed more than $50 \%$ of vertebral body height were observed in $82 \%$ of all cases in tuberculous spondylitis. Such was observed in $30 \%$ of the cases in pyogenic spondylitis. It was concluded that vertebral body was damaged more severely in tuberculous spondylitis than in pyogenic spondylitis. On the other hand, it has been reported that disc is damaged more frequently in pyogenic spondylitis $[41,42]$. Lack of proteolytic enzymes in Mycobacterium as compared with agents of pyogenic infection has been proposed as the cause of the relatively preserved intervertebral disc, found totally sequestered within the involved vertebrae $[1,3,12]$. Chang et al. [41] has reported that $57 \%$ of a disc was preserved in tuberculous spondylitis,
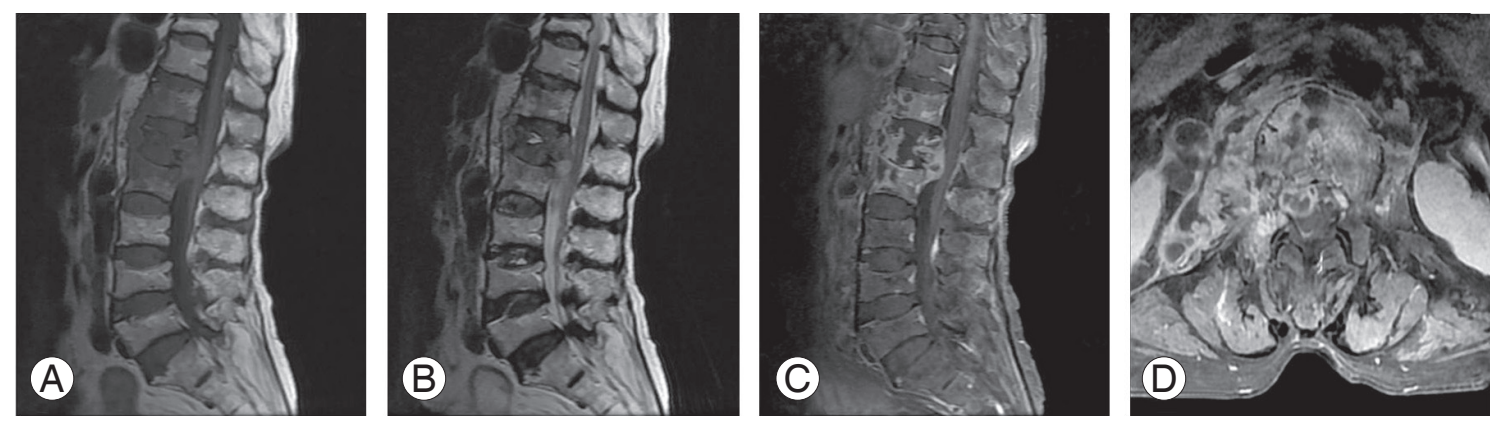

Fig. 1. Magnetic resonance imaging findings of tuberculous spondylitis in a 76-year-old woman. (A) T1 weighted sagittal image demonstrates hypointense signal in T12-L2 vertebral bodies with epidural mass and subligamentous spread from T12 to L2. (B) T2 weighted sagittal image shows heterogeneously hyperintense signal. (C) Contrast enhanced T1 sagittal weighted image shows heterogenous enhancement of T12-L2 vertebral bodies. (D) Axial contrast enhanced T1 weighted image shows paraspinal abnormal enhancement and paraspinal abscess-like lesion with peripheral well-enhanced thick wall.
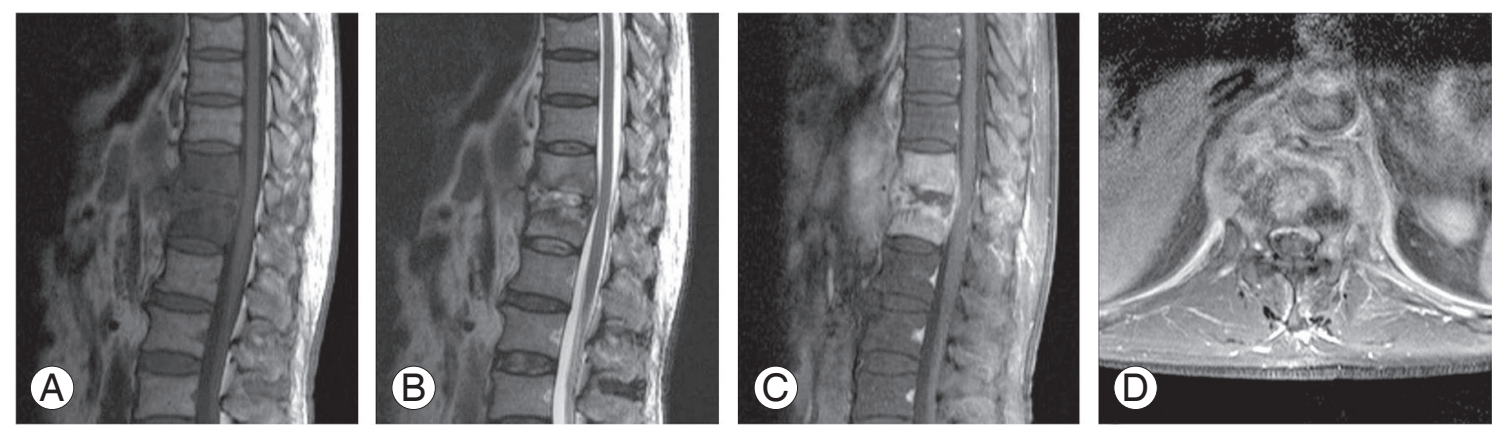

Fig. 2. Magnetic resonance imaging findings of pyogenic spondylitis in a 73-year-old man. (A) Sagittal T1 weighted image shows diffusely decreased signal intensity in T11-T12 vertebral bodies. (B) On sagittal T2 weighted image, T11 and T12 vertebral bodies are isointense to adjacent normal vertebrae. (C) Sagittal contrast enhanced T1 weighted image shows diffuse heterogenous enhancement. Abscess is present in T11-T12 disc space extending to vertebral bodies. (D) Axial contrast enhanced T1 weighted image shows thick and irregular rim enhancement of paraspinal abscess. 
Table 2. Magnetic resonance imaging findings of pyogenic and tuberculous spondylitis

\begin{tabular}{lll}
\hline Variable & Pyogenic spondylitis & Tuberculous spondylitis \\
\hline Para- or intraspinal abscess & Absence & Presence \\
\hline Abscess wall & Thick and irregular & Thin and smooth \\
\hline Postcontrast paraspinal abnormal signal margin & III-defined & Well defined \\
\hline Abscess with postcontrast rim enhancement & Disc abscess & Vertebral intraosseous abscess \\
\hline Vertebral body enhancement pattern & Homogeneous & Heterogeneous and focal \\
\hline Involvement of vertebral bodies & Involvement $\leq 2$ vertebral bodies & Multiple body involvement \\
\hline Commonly involved region & Lumbar spine involvement & Thoracic spine involvement \\
\hline Degree of disc preservation & Moderate to complete disc destruction & Normal to mild disc destruction \\
\hline Bony destruction more than half & Infrequent and mild to moderate & Frequent and more severe \\
\hline
\end{tabular}

while only $3 \%$ was preserved in pyogenic spondylitis. A summary of data regarding the radiologic findings is in Table $2[4,41]$.

\section{Treatment}

The aim of treatment is to eradicate the infection, restore and preserve the structure and function of the spine and alleviate pain.

\section{Conservative management}

Conservative management consists of antimicrobial therapy and non-pharmacological treatments, including physiotherapy and immobilization. Immobilization through bed rest is for pain control and prevention of deformity or neurologic deterioration. Length of time for bed rest, type of orthosis and duration of its use depend on location of the infection, degree of bone destruction and deformity and response to treatment. While initial antimicrobial therapy is almost always administered parenterally, its duration varies considerably. In several studies, the mean parenteral treatment duration is at least from 4 to 6 weeks, followed by oral conversion treatment $[11,12,20,43,44]$. At present, it is recommended that parenteral antibiotic therapy be used in maximal dosage for 6 weeks and followed with an oral course of antibiotics until a resolution of the disease. Criteria for discontinuation of antimicrobial treatment include symptom resolution or improvement and the normalization of ESR or CRP $[20,45]$.

In tuberculous spondylitis, multiple drugs are used because of the potential for resistance to a single agent. Selection of rational combinations of drugs is based on the mechanism of action and toxicity of the agents. A 6-month three-drug regimen including isoniazid, rifampin and pyrazinamide is used for most cases of drugsensitive infection $[24,46]$.

\section{Surgical management}

A surgical treatment is required in the following: to acquire bacteriological or histological verification; if there is severe pain; if clinically important abscess is formed; if there is no response after injecting an appropriate antibiotic; if spine is deformed or such needs to be prevented due to a severe damage to the bone; or if there is neurological paralysis [38,47-50]. An operation may be performed to drain abscesses, to debride sequestered bone and disc, to decompress the spinal cord or to stabilize the spine for the prevention or correction of deformity. There is a broad range of options for the surgical management of spinal infections, which include anterior or posterior approach, single-stage or two-stage surgery and with or without instrumentation. Chen et al. [48] has described a tendency toward a decrease in the incidence of infection recurrence and revision surgery with combined approach as compared with other approaches. Single-stage surgery has advantages including lower complication rate, shorter hospital stay and early mobilization. The two-stage surgery has shorter operation time, less blood loss and increased safety for patients with poorer general health $[51,52]$. The efficacy of the two-staged operation did not differ between the patients with pyogenic and tuberculous spondylitis [53].

In most cases, the spine should be approached anteriorly, as it allows direct access to the infected tissues and adequate debridement. The use of titanium mesh cages 
may provide better anterior column support, because their structural integrity is not affected by degradative enzymes present in an infection environment. Interestingly bacteria show lower propensity of adherence to titanium compared with stainless steel [54-57]. The addition of posterior instrumentation provides even better deformity correction and faster rate of fusion and does not appear to increase the risk of infection [54]. Single-stage anterior and posterior surgery has been shown to be safe and effective using titanium implants $[55,56]$. Recent advances in minimally invasive spine (MIS) techniques offer alternative methods of surgical treatment. Korovessis et al. [58] showed in a small number of patients that anterior debridement and reconstruction with titanium mesh cages followed by posterior MIS screw fixation led to decreased blood loss and shortened operative time.

In tuberculous spondylitis, most authors agree that anterior radical debridement and strut graft fusion is superior. The spine is approached anteriorly so that the affected area may be dealt with most directly. Oga et al. [59] evaluated the adherence properties of $M$. tuberculosis and S. epidermidis to stainless steel. The Staphylococcus heavily colonized the rods and was covered with a thick biofilm, whereas only a few biofilm-covered colonies of M. tuberculosis were seen. These findings have prompted the use of anterior instrumentation at the time of initial anterior debridement. Some authors recommend that a posterior fusion should be performed in addition to an anterior fusion in order to eliminate the risk of increased deformity [60-62]. Anterior grafts may not provide stable fixation, especially in cases where the graft spans more than two-disc spaces [63].

\section{Conclusions}

Pyogenic spondylitis and tuberculous spondylitis entail various types of clinical behavior, and a differential diagnosis is less likely to be conducted. It would be feasible for clinical and radiologic indices to be beneficially utilized on the differential diagnosis, before a culture examination or pathologic examination is performed or in uncertain situations.

\section{Conflict of Interest}

No potential conflict of interest relevant to this article was reported.

\section{Acknowledgments}

This study was supported by Dong-A University Research Funding.

\section{References}

1. Ansari S, Ashraf AN, Moutaery KA. Spine infection: a review. Neurosurg Q 2001;11:112-23.

2. Buchelt M, Lack W, Kutschera HP, et al. Comparison of tuberculous and pyogenic spondylitis: an analysis of 122 cases. Clin Orthop Relat Res 1993;(296):192-9.

3. An HS, Seldomridge JA. Spinal infections: diagnostic tests and imaging studies. Clin Orthop Relat Res 2006;444:27-33.

4. Jung NY, Jee WH, Ha KY, Park CK, Byun JY. Discrimination of tuberculous spondylitis from pyogenic spondylitis on MRI. AJR Am J Roentgenol 2004;182:1405-10.

5. Watson JM. Tuberculosis in Britain today. BMJ 1993;306:221-2.

6. Tsiodras S, Falagas ME. Clinical assessment and medical treatment of spine infections. Clin Orthop Relat Res 2006;444:38-50.

7. Colmenero JD, Jimenez-Mejias ME, Reguera JM, et al. Tuberculous vertebral osteomyelitis in the new millennium: still a diagnostic and therapeutic challenge. Eur J Clin Microbiol Infect Dis 2004;23:477-83.

8. Arizono T, Oga M, Shiota E, Honda K, Sugioka Y. Differentiation of vertebral osteomyelitis and tuberculous spondylitis by magnetic resonance imaging. Int Orthop 1995;19:319-22.

9. Sharif HS, Morgan JL, al Shahed MS, al Thagafi MY. Role of CT and MR imaging in the management of tuberculous spondylitis. Radiol Clin North Am 1995;33:787-804.

10. Rothman RH, Simeone FA. The spine. 5th ed. Philadelphia, PA: Elsevier Saunders; 2006.

11. Canale ST, Beaty JH. Campbell's operative orthopaedics. 11th ed. Philadelphia, PA: Elsevier Mosby; 2008.

12. Herkowitz HN, Garfin SR, Eismont FJ, et al. Rothman-Simeone the spine. 6th ed. Philadelphia, PA: Elsevier Saunders; 2011.

13. Liebergall M, Chaimsky G, Lowe J, Robin GC, Floman Y. Pyogenic vertebral osteomyelitis with paralysis. Prognosis and treatment. Clin Orthop Relat Res 1991;(269):142-50. 
14. Brown MD, Tsaltas TT. Studies on the permeability of the intervertebral disc during skeletal maturation. Spine (Phila Pa 1976) 1976;1:240-4.

15. Kim NH, Chung IH, Chung SM, Lee M. Pyogenic osteomyelitis of the spine. J Korean Orthop Assoc 1977;12:719-30.

16. A controlled trial of anterior spinal fusion and débridement in the surgical management of tuberculosis of the spine in patients on standard chemotherapy: a study in two centres in South Africa. Seventh Report of the Medical Research Council Working Party on tuberculosis of the spine. Tubercle 1978;59:79-105.

17. Hahn MS, Lee HK, Lee DY, et al. Tuberculosis of the spine. Part I: clinical study on anterior fusion for spinal tuberculosis. J Korean Orthop Assoc 1984;19:69-74.

18. Bailey HL, Gabriel M, Hodgson AR, Shin JS. Tuberculosis of the spine in children. Operative findings and results in one hundred consecutive patients treated by removal of the lesion and anterior grafting. J Bone Joint Surg Am 1972;54:1633-57.

19. Hadjipavlou AG, Mader JT, Necessary JT, Muffoletto AJ. Hematogenous pyogenic spinal infections and their surgical management. Spine (Phila Pa 1976) 2000;25:1668-79.

20. Legrand E, Flipo RM, Guggenbuhl P, et al. Management of nontuberculous infectious discitis. treatments used in 110 patients admitted to 12 teaching hospitals in France. Joint Bone Spine 2001;68:504-9.

21. Frederickson B, Yuan H, Olans R. Management and outcome of pyogenic vertebral osteomyelitis. Clin Orthop Relat Res 1978;(131):160-7.

22. Garcia A Jr, Grantham SA. Hematogenous pyogenic vertebral osteomyelitis. J Bone Joint Surg Am 1960;42:429-36.

23. Sapico FL, Montgomerie JZ. Pyogenic vertebral osteomyelitis: report of nine cases and review of the literature. Rev Infect Dis 1979;1:754-76.

24. Pirofsky JG, Huang CT, Waites KB. Spinal osteomyelitis due to Mycobacterium avium-intracellulare in an elderly man with steroid-induced osteoporosis. Spine (Phila Pa 1976) 1993;18:1926-9.

25. Wiley AM, Trueta J. The vascular anatomy of the spine and its relationship to pyogenic vertebral osteomyelitis. J Bone Joint Surg Br 1959;41:796-809.

26. Smith AS, Weinstein MA, Mizushima A, et al. MR imaging characteristics of tuberculous spondylitis vs vertebral osteomyelitis. AJR Am J Roentgenol 1989;153:399-405.

27. Griffith JF, Kumta SM, Leung PC, Cheng JC, Chow LT, Metreweli C. Imaging of musculoskeletal tuberculosis: a new look at an old disease. Clin Orthop Relat Res 2002;(398):32-9.

28. Lee KY, Sohn SK, Hwang KS. Comparison of pyogenic and tuberculous spondylitis. J Korean Soc Spine Surg 1999;6:443-50.

29. Koo KH, Lee HJ, Chang BS, Yeom JS, Park KW, Lee CK. Differential diagnosis between tuberculous spondylitis and pyogenic spondylitis. J Korean Soc Spine Surg 2009;16:112-21.

30. Digby JM, Kersley JB. Pyogenic non-tuberculous spinal infection: an analysis of thirty cases. J Bone Joint Surg Br 1979;61:47-55.

31. Schulitz KP, Assheuer J. Discitis after procedures on the intervertebral disc. Spine (Phila Pa 1976) 1994;19:1172-7.

32. Berk RH, Yazici M, Atabey N, Ozdamar OS, Pabuccuoglu U, Alici E. Detection of Mycobacterium tuberculosis in formaldehyde solution-fixed, paraffinembedded tissue by polymerase chain reaction in Pott's disease. Spine (Phila Pa 1976) 1996;21:1991-5.

33. Kim NH, Lee HM, Suh JS. Magnetic resonance imaging for the diagnosis of tuberculous spondylitis. Spine (Phila Pa 1976) 1994;19:2451-5.

34. Hong SH, Kim SM, Ahn JM, Chung HW, Shin MJ, Kang HS. Tuberculous versus pyogenic arthritis: MR imaging evaluation. Radiology 2001;218:848-53.

35. Harada Y, Tokuda O, Matsunaga N. Magnetic resonance imaging characteristics of tuberculous spondylitis vs. pyogenic spondylitis. Clin Imaging 2008;32:303-9.

36. An HS, Vaccaro AR, Dolinskas CA, Cotler JM, Balderston RA, Bauerle WB. Differentiation between spinal tumors and infections with magnetic resonance imaging. Spine (Phila Pa 1976) 1991;16(8 Suppl):S334-8.

37. Moore SL, Rafii M. Imaging of musculoskeletal and spinal tuberculosis. Radiol Clin North Am 2001;39:329-42.

38. Hsieh PC, Wienecke RJ, O'Shaughnessy BA, Koski TR, Ondra SL. Surgical strategies for vertebral osteomyelitis and epidural abscess. Neurosurg Focus 2004;17:E4.

39. Moorthy S, Prabhu NK. Spectrum of MR imaging 
findings in spinal tuberculosis. AJR Am J Roentgenol 2002;179:979-83.

40. Shanley DJ. Tuberculosis of the spine: imaging features. AJR Am J Roentgenol 1995;164:659-64.

41. Chang MC, Wu HT, Lee CH, Liu CL, Chen TH. Tuberculous spondylitis and pyogenic spondylitis: comparative magnetic resonance imaging features. Spine (Phila Pa 1976) 2006;31:782-8.

42. Varma R, Lander P, Assaf A. Imaging of pyogenic infectious spondylodiskitis. Radiol Clin North Am 2001;39:203-13.

43. Musher DM, Thorsteinsson SB, Minuth JN, Luchi RJ. Vertebral osteomyelitis: still a diagnostic pitfall. Arch Intern Med 1976;136:105-10.

44. Osenbach RK, Hitchon PW, Menezes AH. Diagnosis and management of pyogenic vertebral osteomyelitis in adults. Surg Neurol 1990;33:266-75.

45. McHenry MC, Easley KA, Locker GA. Vertebral osteomyelitis: long-term outcome for 253 patients from 7 Cleveland-area hospitals. Clin Infect Dis 2002;34:1342-50.

46. Haas DW, Des Prez RM. Mycobacterium tuberculosis. In: Mandell GL, Bennett JE, Dolin RL, editors. Principles and practices of infectious diseases. 4th ed. New York: Churchill Livingstone; 1995. p.2213-43.

47. Quinones-Hinojosa A, Jun P, Jacobs R, Rosenberg WS, Weinstein PR. General principles in the medical and surgical management of spinal infections: a multidisciplinary approach. Neurosurg Focus 2004;17:E1.

48. Chen WH, Jiang LS, Dai LY. Surgical treatment of pyogenic vertebral osteomyelitis with spinal instrumentation. Eur Spine J 2007;16:1307-16.

49. Lehovsky J. Pyogenic vertebral osteomyelitis/disc infection. Baillieres Best Pract Res Clin Rheumatol 1999;13:59-75.

50. Darouiche RO. Spinal epidural abscess. N Engl J Med 2006;355:2012-20.

51. Korovessis P, Petsinis G, Koureas G, Iliopoulos P, Zacharatos S. One-stage combined surgery with mesh cages for treatment of septic spondylitis. Clin Orthop Relat Res 2006;444:51-9.

52. Fukuta S, Miyamoto K, Masuda T, et al. Two-stage (posterior and anterior) surgical treatment using posterior spinal instrumentation for pyogenic and tuberculotic spondylitis. Spine (Phila Pa 1976) 2003;28:E302-8.

53. Masuda T, Miyamoto K, Hosoe H, Shimizu K. Com- parative study on the efficacy of two-staged (posterior followed by anterior) surgical treatment using spinal instrumentation on pyogenic and tuberculotic spondylitis. Arch Orthop Trauma Surg 2011;131:765-72.

54. Hee HT, Majd ME, Holt RT, Pienkowski D. Better treatment of vertebral osteomyelitis using posterior stabilization and titanium mesh cages. J Spinal Disord Tech 2002;15:149-56.

55. Ha KY, Chung YG, Ryoo SJ. Adherence and biofilm formation of Staphylococcus epidermidis and Mycobacterium tuberculosis on various spinal implants. Spine (Phila Pa 1976) 2005;30:38-43.

56. Barth E, Myrvik QM, Wagner W, Gristina AG. In vitro and in vivo comparative colonization of Staphylococcus aureus and Staphylococcus epidermidis on orthopaedic implant materials. Biomaterials 1989;10:325-8

57. Sundararaj GD, Amritanand R, Venkatesh K, Arockiaraj J. The use of titanium mesh cages in the reconstruction of anterior column defects in active spinal infections: can we rest the crest? Asian Spine J 2011;5:155-61.

58. Korovessis P, Repantis T, Iliopoulos P, Hadjipavlou A. Beneficial influence of titanium mesh cage on infection healing and spinal reconstruction in hematogenous septic spondylitis: a retrospective analysis of surgical outcome of twenty-five consecutive cases and review of literature. Spine (Phila Pa 1976) 2008;33:E759-67.

59. Oga M, Arizono T, Takasita M, Sugioka Y. Evaluation of the risk of instrumentation as a foreign body in spinal tuberculosis: clinical and biologic study. Spine (Phila Pa 1976) 1993;18:1890-4.

60. Kemp HB, Jackson JW, Shaw NC. Laminectomy in paraplegia due to infective spondylosis. Br J Surg 1974;61:66-72.

61. Moon MS, Kim I, Woo YK, Park YO. Conservative treatment of tuberculosis of the thoracic and lumbar spine in adults and children. Int Orthop 1987;11:31522.

62. Lee JC, Kim YI, Shin BJ. Safety and efficacy of pedicle screws and titanium mesh cage in the treatments of tuberculous spondylitis of the thoracolumbar spine. Asian Spine J 2008;2:64-73.

63. Rajasekaran S, Soundarapandian S. Progression of kyphosis in tuberculosis of the spine treated by anterior arthrodesis. J Bone Joint Surg Am 1989;71:1314-23. 